\title{
Histological study of rat ovaries cryopreserved by vitrification or slow freezing and reimplanted in the early or late postmenopausal stage ${ }^{1}$
}

\author{
João Marcos de Meneses e Silva ${ }^{\mathrm{I}}$, Luiz Gonzaga Porto Pinheiro ${ }^{\mathrm{II}}$, José Alberto Dias Leite ${ }^{\mathrm{III}}$, Lígia Helena Ferreira Melo ${ }^{\mathrm{IV}}$, \\ Franciele Osmarini Lunardi ${ }^{\mathrm{V}}$, Rômulo Cesar Costa Barbosa Filho ${ }^{\mathrm{VI}}$, Cindy Vitalino Mendonça ${ }^{\mathrm{VII}}$
}

\author{
DOI: http://dx.doi.org/10.1590/S0102-86502014000500003
}

IFellow PhD degree, Postgraduate Program in Medical and Surgical Sciences, Department of Surgery, School of Medicine, Federal University of Ceara (UFC), Fortaleza-CE, Brazil. Design of the study, technical procedures, analysis and interpretation of data, manuscript writing, critical revision. IIPhD, Full Professor, Department of Surgery, School of Medicine, UFC, Fortaleza-CE, Brazil. Scientific and intellectual content of the study, critical revision.

IIIPhD, Full Professor, Department of Surgery, School of Medicine, UFC, Fortaleza-CE, Brazil. Scientific and intellectual content of the study.

${ }^{\mathrm{I}} \mathrm{MD}$, Department of Radiology, General Army Hospital of Fortaleza, Fortaleza-CE, Brazil. Technical procedures; acquisition, analysis and interpretation of data.

${ }^{\mathrm{v}}$ Master Veterinarian, Veterinary Medicine, Veterinary School, State University of Ceara (UECE), Fortaleza-CE, Brazil. Technical procedures; scientific and intellectual content of the study.

VIResident, Department of Surgery, Hospital Nossa Senhora da Conceição, Fortaleza-CE, Brazil. Acquisition of data, technical procedures.

${ }^{\mathrm{VII}}$ Graduate student, School of Medicine, UFC, Fortaleza-CE, Brazil. Technical procedures, English language.

\section{ABSTRACT}

PURPOSE: To compare two rat ovary cryopreservation techniques (vitrification vs. slow freezing) and two postmenopausal stages (early vs. late) with regard to graft take.

METHODS: Thirty-three Wistar rats were submitted to bilateral oophorectomy. One ovary was submitted to histological analysis while the other was cryopreserved by slow freezing or vitrification. The cryopreserved ovary was thawed and reimplanted in the greater omentum one week (early menopause) or one month (late menopause) after oophorectomy. One month after ovary reimplantation, the graft take was evaluated macroscopically and histologically.

RESULTS: Six of the animals were used ascontrols and seven died. The histological findings of 20 animals included atretic follicles $(n=4)$, primordial follicles $(n=2)$, and corpus luteum with primordial follicles $(n=3)$. No ovarian tissue was found in 11 animals. Vitrification resulted in a higher graft take rate than slow freezing ( $50 \%$ vs. $38.5 \%)$, but the difference was not statistically significant. However, the graft take rate was 9.3 times higher in the early than in the late postmenopausal stage $(61.5 \%$ vs. $14.3 \%)(p=0.043)$.

CONCLUSION: Vitrification was superior to slow freezing as ovarian cryopreservation technique, and grafting was significantly more successful when the ovary was reimplanted in the late postmenopausal stage.

Key words: Cryopreservation. Vitrification. Ovariectomy. Rats. 


\section{Introduction}

With the advent of new therapies against chronic degenerative diseases, especially neoplasia, the life expectancy of many young patients has been extended. Ovarian function may be lost prematurely as a result of treatment for neoplasia (depending on the age of patient), the chemotherapy regimen and the irradiation levels used. In addition, even though ovulation resumes after oncological treatment, fertility may have been compromised.

For such patients, the maintenance of ovarian function is often a priority, with direct implications on future quality of life ${ }^{1}$. Thus, many women seek medical care in an attempt to postpone the menopause and its complications and maintain ovarian function as long as possible.

The menopause can be a very distressing and debilitating period, with a range of accompanying manifestations, including vasomotor symptoms, insomnia, headache, genito-urinary disorders, fluctuations in libido, bone-joint changes and osteoporosis ${ }^{2}$.

In a recently published review, chances of spontaneous gestation were estimated at $28 \%$ and $5 \%$ for women under 20 and over 25 years of age, respectively, following treatment for cancer with radiotherapy and chemotherapy ${ }^{3}$.

Cryopreservation is an experimental fertility preservation technique involving the surgical removal and cryopreservation of the ovaries of mostly young women prior to chemotherapy in order to avoid exposure to systemic gonadotoxic compounds. Following treatment, provided the patient is believed to be disease-free, the ovaries may be reimplanted. Though still in the experimental stage, cryopreservation is considered a promising alternative for the recovery of fertility ${ }^{4-5}$.

The recovery of ovarian function by way of reimplantation of cryopreserved tissue has been successfully accomplished in both animals and humans. However, due to the small number of patients submitted to this procedure so far, the technique has not been fully standardized ${ }^{6-7}$.

Several animal models have been designed to evaluate compounds capable of improving the techniques and outcomes of cryopreservation. Over time, a number of different compounds have been used in the cryopreservation of reproductive cells. Thus, several studies were conducted in the 1990s evaluating the cryoprotective efficiency of DMSO, ethylene glycol, propylene glycol and even glycerol (used since 1949) ${ }^{7}$.

Initially, most research was focused on the cryopreservation of spermatozoa. Already in 1951, the first calf was born using frozen bull sperm. The new techniques facilitated selection and reproduction of domestic animals. Eventually, cryopreservation techniques were adapted for use in human organs, at first for oocytes and follicles, then for ovaries and embryos ${ }^{8-9}$.

In 1954, for the first time, a child was born as the result of insemination with semen stored for six weeks in dry ice. Ten years later, in 1964, a child was born which had been conceived with semen stored in liquid nitrogen for five months. More recently, with the advent in 2004 of proper cryopreservation techniques, a child was engendered using semen frozen for 21 years, making the duration of the seminal phase of human life practically unlimited ${ }^{10-11}$.

The evolution of techniques of cryopreservation of female germ cells has been remarkable. The first studies on ovarian tissue cryopreservation were performed in rodents more than half a century ago, and results have been very encouraging since. Current achievements include the maintenance of the morphology and viability of the ovarian follicle structure and the restoration of endocrine function after cryopreservation and transplantation of ovarian tissue.

After orthotopic transplantation of previously frozen and thawed whole ovary, Parrott ${ }^{12}$ described the first birth: a single offspring in mice. Using a similar protocol, other researchers obtained mouse pregnancy rates between 33\% and 73\% and 3-4 births per litter. Yet others reported promising results (23 births) after orthotopic transplantation of frozen/thawed half ovaries, demonstrating that ovarian tissue retrieved post-mortem was viable even after a period of storage at low temperatures ${ }^{13}$.

In 2004, Donnez and colleagues published an important study on human reproductive medicine particularly relevant to young women facing the prospect of gonadotoxic treatment. One of their patients experienced restoration of her endocrine and gametogenic functions and conceived 11 months after orthotopic autotransplantation of ovarian fragments ${ }^{6}$.

The study showed that women treated for and cured of cancer can bear healthy children without the use of assisted reproduction techniques such as in vitro fertilization ${ }^{4,7}$. More recently, other researchers demonstrated that it is possible to maintain endocrine and gametogenic activity in the graft for an extended period. One of their patients was submitted to ovarian tissue transplantation after treatment for cancer ${ }^{14}$.

The overall purpose of cryopreservation is graft integrity through the maintenance of the anatomical and functional viability of cell structures. The success of cryopreservation depends on a range of technical factors: freeze-storage time and temperature, type and amount of cryoprotectors used, the osmolar concentration of the medium, and changes in cell 
volume, structure and function, especially related to plasma membrane permeability and fluidity and its implications for cell metabolism. The main complication is cryoinjury which involves one or more successive or independent events: formation of intracellular and extracellular ice crystals, chemical toxicity of cryoprotectors, osmotic shock and fracture damage ${ }^{15}$.

Proper training in the techniques of cryopreservation and autotransplantation in animals is indispensable for surgeons who wish to offer this treatment option for patients in whom ovarian function may be compromised by radio and chemotherapy.

\section{Methods}

The experimental protocols were reviewed and approved by the Ethics Committee for Animal Research of the Federal University of Ceara and filed under entry number 79/2012.

The study used thirty-three-month-old female Wistar rats (RattusNovergicus) weighing approximately $200 \mathrm{~g}$. The animals were housed in individual cages in a controlled environment (circadian cycle, $22 \pm 2^{\circ} \mathrm{C}$, constant humidity, food and water ad libitum).

\section{Ovarian tissue}

Following excision, the ovaries $\left(\sim 2 \mathrm{~mm}^{3}\right)$ were dissected free of fat and mesentery. One of the ovaries was submitted to histological analysis; the other was cryopreserved.

\section{Design of the experiment}

Stage I: Thirty-three Wistar rats were submitted to bilateral oophorectomy. One ovary was immediately submitted to histological analysis, while the other was cryopreserved by slow freezing $(n=10)$ or vitrification $(n=23)^{7,16}$. Two animals from the slow freezing group and five animals from the vitrification group died. The controls included six animals from the vitrification group and two from the slow-freezing group. The latter two animals provided sufficient material for control and experimental procedures.

Stage II: The cryopreserved ovary was thawed and reimplanted in the greater omentum one week after oophorectomy (early menopause) (Group A, n=7; 3 vitrified and 4 slow-frozen) or one month after oophorectomy (late menopause) (Group B, $\mathrm{n}=13 ; 9$ vitrified and 4 slow-frozen).

Stage III: One month after ovary reimplantation, the animals were euthanized, the graft was excised and graft take was evaluated.

\section{Vitrification and warming procedures}

Whole ovaries were initially equilibrated in HEPES containing $10 \% \mathrm{v} / \mathrm{v}$ ethylene glycol and $10 \% \mathrm{v} / \mathrm{v}$ DMSO for $20 \mathrm{~min}$ at room temperature and then immersed for $3 \mathrm{~min}$ in a vitrification solution containing $17 \% \mathrm{v} / \mathrm{v}$ ethylene glycol, $17 \% \mathrm{v} / \mathrm{v}$ DMSO and $0.75 \mathrm{M}$ sucrose in HEPES. The ovaries were then transferred individually with minimal vitrification solution to the surface of a metal cube floating in liquid nitrogen. The vitrified ovaries were kept in liquid nitrogen $\left(-196^{\circ} \mathrm{C}\right)$ for $30-60 \mathrm{~min}$. Using cooled forceps, the samples were placed in cooled cryovials containing liquid nitrogen, according to a protocol adapted from Wang et al. ${ }^{16}$ Prior to reimplantation, the vials containing the samples were removed from liquid nitrogen storage and exposed to room temperature for one minute. Then each sample was submitted to three 5-min baths in a solution containing minimal essential medium $+10 \%$ fetal calf serum and decreasing concentrations of sucrose $(0.5,0.25$ and $0.0 \mathrm{M})$, using a protocol adapted from Lunardiet $a l .{ }^{7}$.

\section{Slow freezing}

The procedure was carried out according to the protocol described by Gosden et al. ${ }^{17}$. Ovarian strips were placed in 2-mL cryovials filled with a cryoprotective solution containing modified phosphate-buffered saline (DPBS) medium, $1.5 \mathrm{mmol} / \mathrm{LDMSO}$ and $20 \%$ human serum albumin (HSA). Using a programmable freezer (Custom BioGenic Systems Model 2100 Controlled Rate Freezing System), the cryovials were i) cooled from $0^{\circ} \mathrm{C}$ to $-8^{\circ} \mathrm{C}$ at $-2^{\circ} \mathrm{C} / \mathrm{min}$; ii) cooled to $-40^{\circ} \mathrm{C}$ at $-0.3^{\circ} \mathrm{C} / \mathrm{min}$; (iii) cooled to $-150^{\circ} \mathrm{C}$ at $-30^{\circ} \mathrm{C} /$ min, and (iv) immediately transferred to liquid nitrogen for storage at $-196^{\circ} \mathrm{C}$. To thaw the ovarian cortical tissue, the cryovials were removed from the dewarand kept at room temperature for $2 \mathrm{~min}$, followed by immersion in a water bath at $37^{\circ} \mathrm{C}$ for 2 min under gentle shaking. The contents of the cryovials were quickly emptied into culture dishes with Leibovitz L-15 medium and washed three times with fresh medium to remove residual cryoprotector before further processing.

\section{Histology}

Samples of the ovaries were submitted to histological analysis at three different moments: i) upon oophorectomy, when the ovaries were presumed to have a normal production of follicles, ii) upon thawing, in order to compare the outcome of the two freezing techniques (slow freezing and vitrification), and iii) upon euthanasia, in order to evaluate graft take one month after ovary reimplantation 
in both early (one week) and late (one month) postmenopausal rats ${ }^{18}$.

\section{Statistical analysis}

The study variables were dichotomous (presence/absence). Using the software GraphPadPrism 5.0, findings were submitted to Fisher's exact test and expressed as absolute frequencies and percentages. The level of statistical significance was set at $5 \%(p<0.05)$.

\section{Results}

\section{Slow freezing}

Two of the 10 rats which received an ovarian graft cryopreserved by slow freezing died (mortality: 20\%). The graft was evaluated for viability prior to reimplantation in two $(25 \%)$ of the eight surviving animals. In one of these (50\%), primordial follicles and corpus luteum were observed, matching findings in the literature (42\%). Upon euthanasia, no ovarian graft was found in five (62.5\%) animals. In the remaining three animals $(38.5 \%)$, the graft had taken. One of these $(12.8 \%)$ presented atretic follicles while $2(25.6 \%)$ presented primordial follicles and corpus luteum (Table 1). All three animals with successful grafting belonged to Group B (late postmenopausal stage).

\section{Vitrification}

Five of the 23 rats which received an ovarian graft cryopreserved by vitrification died (mortality: 15.1\%). Six randomly selected grafts evaluated for viability (but not implanted) presented primordial follicles and corpus luteum $(5 / 6 ; 83.3 \%)$ and atretic and primordial follicles $(1 / 6 ; 16.7 \%)$. The remaining 12 grafts were implanted. Upon euthanasia, no ovarian graft was found in six $(50 \%)$ animals, just inflammatory/scar tissue and/or fibrosis. In the other six animals (50\%), the graft had taken (Figure 1).

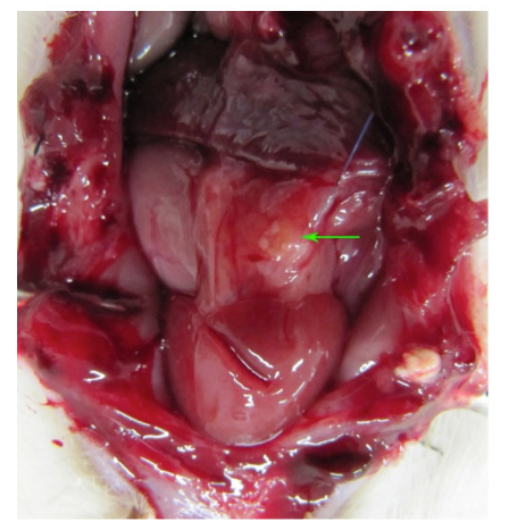

FIGURE 1 - Abdominal cavity of female Wistar rat after laparotomy showing ovary (arrow) reimplanted in the omentum. The color of the tissue and the absence of macroscopic evidence of necrosis are suggestive of good graft take.

TABLE1 - Histological findings following reimplantation of ovarian tissue in 20 female Wistar rats.

\begin{tabular}{|c|c|c|c|c|c|}
\hline \multicolumn{6}{|c|}{ Ovary cryopreservation and reimplantation } \\
\hline \multirow{2}{*}{ ANIMAL } & \multicolumn{2}{|c|}{ Postmenopausal stage } & \multirow{2}{*}{ Histological findings following reimplantation } & \multicolumn{2}{|c|}{ Cryopreservation technique } \\
\hline & Early & Late & & Vitrification & Slow freezing \\
\hline 1 & & $\mathrm{X}$ & $\mathrm{PF}+\mathrm{CL}$ & $\mathrm{X}$ & \\
\hline 2 & & $\mathrm{X}$ & $\mathrm{AF}$ & $X$ & \\
\hline 3 & $\mathrm{X}$ & & $\mathrm{AF}+\mathrm{PF}$ & $\mathrm{X}$ & \\
\hline 4 & & $\mathrm{X}$ & $\mathrm{AF}$ & $\mathrm{X}$ & \\
\hline 5 & & $X$ & Absence of ovarian tissue & $X$ & \\
\hline 6 & & $\mathrm{X}$ & $\mathrm{AF}$ & $\mathrm{X}$ & \\
\hline 7 & $\mathrm{X}$ & & Absence of ovarian tissue & $\mathrm{X}$ & \\
\hline 8 & $\mathrm{X}$ & & Absence of ovarian tissue & $\mathrm{X}$ & \\
\hline 9 & & $\mathrm{X}$ & Absence of ovarian tissue & $\mathrm{X}$ & \\
\hline 10 & & $\mathrm{X}$ & Absence of ovarian tissue & $\mathrm{X}$ & \\
\hline 11 & & $\mathrm{X}$ & $\mathrm{AF}+\mathrm{PF}$ & $X$ & \\
\hline 12 & & $X$ & Absence of ovarian tissue & $\mathrm{X}$ & \\
\hline 13 & $\mathrm{X}$ & & Absence of ovarian tissue & & $\mathrm{X}$ \\
\hline 14 & $\mathrm{x}$ & & Absence of ovarian tissue & & $\mathrm{X}$ \\
\hline 15 & $\mathrm{x}$ & & Absence of ovarian tissue & & $\mathrm{X}$ \\
\hline 16 & & $\mathrm{x}$ & $\mathrm{AF}$ & & $\mathrm{X}$ \\
\hline 17 & & $\mathrm{x}$ & Absence of ovarian tissue & & $\mathrm{X}$ \\
\hline 18 & $\mathrm{X}$ & & Absence of ovarian tissue & & $\mathrm{X}$ \\
\hline 19 & & $\mathrm{X}$ & $\mathrm{PF}+\mathrm{CL}$ & & $\mathrm{X}$ \\
\hline 20 & & $X$ & $\mathrm{PF}+\mathrm{CL}$ & & $\mathrm{X}$ \\
\hline
\end{tabular}

Legend: $\mathrm{CL}=$ corpus luteum; $\mathrm{AF}=$ atretic follicles; $\mathrm{PF}=$ primordial follicles. 
Three of these (25\%) presented atretic follicles, 2 (16.7\%) presented both atretic and primordial follicles, and one $(8.3 \%)$ presented primordial follicles and corpus luteum (Figures 2 and 3).

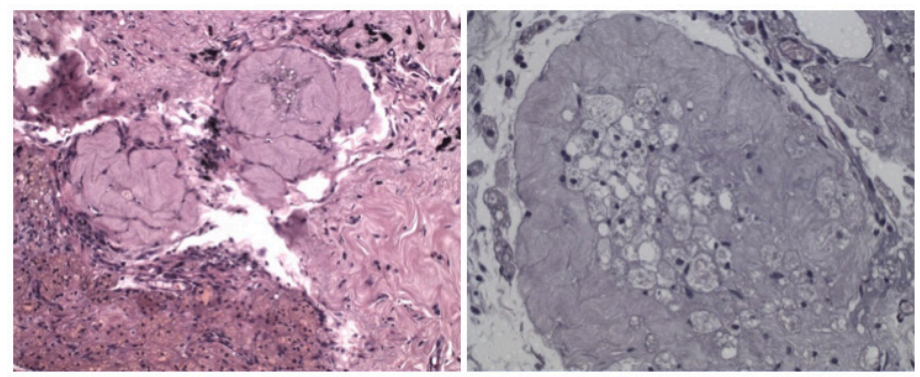

FIGURE 2 - Atretic follicles after reimplantation (Magnification: x200 and $\mathrm{x} 400$ ).

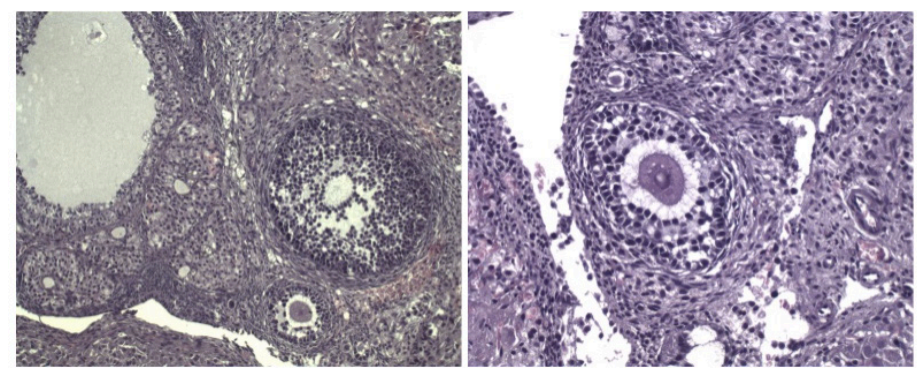

FIGURE 3 - Primordial follicles and corpus luteum after reimplantation (Magnification: x200 and x400).

Most (5/6) of the animals with successful grafting belonged to Group B (late postmenopausal stage) (Group B=83.3\% vs. Group $\mathrm{A}=16.7 \%$ ), but the difference between the groups with regard to take rate was not statistically significant $(p=0.080)$.

\section{Slow freezing vs. vitrification}

Upon thawing, the ovarian tissue was preserved in 50\% of slow-frozen specimens versus $100 \%$ of vitrified specimens; however, the difference was not statistically significant $(p=0.400)$. Vitrification resulted in a higher graft take rate than slow freezing (50\% vs. $37.5 \%)$, but the difference was not statistically significant $(p=0.400)$.

\section{Postmenopausal stage}

Six of the seven deaths mentioned in the section describing the designof the study involved animals in the early postmenopausal stage (Group A). The high mortality in this group $(6 / 13 ; 46 \%)$ when compared to that of Group B $(1 / 13 ; 7 \%)$ may be explained by surgical stress, considering the short period elapsed (one week) between oophorectomy and reimplantation. Thus, mortality was not related to the cryopreservation technique employed but to the timing of the two surgical interventions.
Of the 20 animals in the final sample, seven belonged to Group A (early postmenopause) and 13 belonged to Group B (late menopause). In the latter group, nine ovaries were vitrified, followed by five $(55.5 \%)$ successful reimplantations, while four ovaries were slow-frozen, followed by only one successful reimplantation (25\%). Nevertheless, the difference between the techniques did not reach statistical significance $(p=0.559)$.In Group A, three ovaries were vitrified, followed by one $(33.3 \%)$ successful reimplantation, while four ovaries were slow-frozen, with no successful reimplantation $(0 \%)$. Again, the difference was not significant ( $p=0.429$ ). However, when the two postmenopausal stages (early vs. late) were compared with regard to graft take, a statistically significant difference emerged: the graft take rate was 9.3 times higher in late postmenopausal rats $(61.5 \%)$ than in early postmenopausal rats $(14.3 \%)(p=0.043)$.

\section{Discussion}

Despite being a promising technique, ovarian tissue cryopreservation has only resulted in about 20 human live births so far. Much research is needed to improve success rates for both slow-frozen and vitrified tissue and to ensure the health of children born from such treatments. In one study, for example, 27 patients received similar treatments, eight had evidence of antral follicle growth and oocytes were retrieved, but only one gave birth ${ }^{19}$.

In the current study, we used a rat model to compare two cryopreservation techniques (slow freezing vs. vitrification) and to evaluate the influence of postmenopausal status (early vs. late) on graft take. Our findings raise questions about the ideal moment of ovary reimplantation in relation to hormonal metabolism. In other words, the time of absence of ovarian function appears to determine how the organism reacts to reimplantation.

Vitrification resulted in a higher graft take rate than slow freezing (50\% vs. $38.5 \%)$ and follicles were present in all specimens. The success rate of slow freezing was similar to the rates reported in the literature: in vitro studies suggest that vitrification of ovarian tissue may be an improvement over the $70 \%$ oocyte viability loss from slow freezing ${ }^{7}$.

During the 2009 World Congress on Fertility Preservation in Belgium, a list was given of the advantages and disadvantages of vitrification as applied to human ovary cryopreservation. The advantages included i) excellent survival of ovarian stroma and blood vessels, ii) the technique is quick to perform, iii) no sophisticated equipment is needed, iv) the technique is clinically feasible, and v) excellent survival in tissue culture. On the other hand, the disadvantages included i) no live births reported until 
2009 , ii) the technique requires a considerable level of training, iii) the technique is very sensitive to concentrations, osmolarities and swiftness of procedure, and iv) ovarian tissues may be damaged by toxicity if the surgeon is not properly trained. However, recent studies describing human births following ovarian cryopreservation and reimplantation, along with the findings of the current study, indicate that the technique has been mastered despite its complexity.

The subject of rat postmenopausal status has been little discussed in the literature. In our experiment, a significant difference was observed between early and late postmenopausal rats (Groups A and B) with regard to graft take rates. This finding may be interpreted in light of two important studies, one by LópezGrueso et al. ${ }^{20}$ and one by Ahmed et al. ${ }^{18}$.

The first study looked at oxidative stress and estrogen replacement therapy (ERT) at different stages of the menopause (early vs. late). Early, but not late, onset of ERT was found to prevent an ovariectomy-associated increase in mitochondrial hydrogen peroxide levels, oxidative damage to lipids and proteins, and a decrease in glutathione peroxidase and catalase activity in rats. The authors concluded that, possibly, the ER $\alpha / \beta$ ratio is increased by ovariectomy and reduced by immediate estrogen replacement. On positron emission tomography, the former decreased brain glucose uptake in vivo while the latter was beneficial when administered immediately after deprivation. Ovariectomy decreases GLUT-1 and 3 glucose transporters in the brain, and only early onset estrogen administration prevents it. Plasma from rats treated with estrogen immediately after ovariectomy show similar metabolomics profiles as controls. The authors provided a molecular basis for the recommendation of early onset ERT and explained its lack of effectiveness if a significant time period elapses after ovariectomy and probably after the onset of menopause $\mathrm{e}^{20}$. The finding of a better physiological response to ERT during early, rather than late, menopause contradicts the findings of the present study.

The second study, which evaluated mammary gland response to ERT in rodents, found the treatment to be more effective in late postmenopausal animals. The authors examined the effects of ERT on mammary gland morphology, cell proliferation and progesterone receptor regulation in early postmenopause (one week post-ovariectomy) and late postmenopause (five weeks post-ovariectomy). The study explored the effects of ERT on the early vs. late postmenopausal mammary gland and demonstrated that late ovariectomy-induced menopause was associated with improved proliferative response to estrogen, as shown morphologically by pronounced duct end hyperplasia. This enhanced mitogenic response to estrogen was localized to the duct end epithelium (4-fold increase) and adjacent stromal cells (6.5-fold increase). Long-term estrogen treatment produced a lower steady-state proliferative response. However, both epithelial and stromal cell proliferations were 2 -fold higher when long-term estrogen treatment was started at 5 weeks post-ovariectomy vs. 1 week post-ovariectomy. In other words, an apparent permanent enhanced proliferative response to estrogen was observed in late postmenopausal animals. In contrast, no morphological response and minimal epithelial and stromal cell proliferation were observed after any length of estrogen treatment in early postmenopausal animals ${ }^{18}$.

Our results suggest that, despite claims of improved effects in relation to oxidative stress during early postmenopausal stages, ovarian graft take rates are higher in the late postmenopausal stage than in the early postmenopausal stage. This is supported by the enhanced mammary gland response to ERT observed in late postmenopausal rodents.

Vitrification was shown to be superior to slow freezing as ovarian cryopreservation technique, and grafting was significantly more successful when the ovary was reimplanted in the late postmenopausal stage. These results may be helpful in future studies, especially when determining the ideal time of onset of ERT in women.

\section{Conclusions}

Both vitrification and slow freezing were feasible though the former yielded better results when the time of reimplantation was taken into account. Regardless of the time of cryopreservation, rat ovary reimplantation is more likely to be successful in the late postmenopausal stage.

\section{References}

1. Teinturier C, Hartmann O, Valteau-Couanet D, Benhamou E, Bougneres PF. Ovarian function after autologous bone marrow transplantation in childhood: High-dose busulfan is a major cause of ovarian failure. Bone Marrow Transplant. 1998;22:989-94.

2. Binkley N, Krueger D. Combination therapy for osteoporosis: considerations and controversy. Curr Osteporos Rep. 2005;3:150-4.

3. Lobo RA. Potential options for preservation of fertility in women. $\mathrm{N}$ Engl J Med. 2005;353:64-73.

4. Lee SJ, Schover LR, Partridge AH Patrizio P, Wallace HW, Hagerty K, Beck LN, Brennan VL, Oktay K. American Society of Clinical Oncology recommendations on fertility preservation in cancer patients. J ClinOncol. 2006;24:2917-31.

5. Oktay K, Karlikaya G. Ovarian function after transplantation of frozen, banked autologous ovarian tissue. N Engl J Med. 2000;342:1919.

6. Oktay K, Tilly J. Live birth after cryopreserved ovarían tissue autotransplantation. Lancet. 2004;364:2091-2. 
7. Lunardi FO, Araújo VR, Faustino LR, Carvalho AA, Gonçalves RFB, Bass CS, BAO SN, OlaziaName KP, Campello CC, De Figueiredo JR, Ribeiro Rodrigues APl. Morphologic, viability and ultrastructural analysis of vitrified sheep preantralfollicles en closed in ovarían tissue. Small Rumin Res. 2012;107:121-30

8. Polge C. Fertilizing capacity of bull spermatozoa after freezing at degrees C. Nature. 1952;169(4302):626-7.

9. Stewart DL. Storage of bull spermatozoa at low temperatures. Vet Rec.1951;63:65-6.

10. Bunge RG, Keettel WC, Sherman JK. Clinical use of frozen semen: report of four cases. Fertil Steril. 1954;5(6):520-9.

11. Horne G, Atkinson AD, Pease EH, Logue JP, Brison DR, Lieberman BA.Live birth with sperm cryopreserved for 21 years prior to cancer treatment: case report. Hum Reprod. 2004;19:1448-9.

12. Parrot DMY. The fertility of mice with orthopic ovarian grafts derived from frozen tissue. J Reprod Fertil. 1960;1:230-41.

13. Mukaida T, Nakamura S, Tomiyama T, Wada S, Kasai M, Takahashi K. Successful birth after transfer of vitrified human blastocysts with use of a cryoloop containerless technique. Fertil Steril. 2001;76(3):618-20.

14. Ernst E, Bergholdt S, Jorgensen JS, Andersen CY. The first woman to give birth to two children following transplantation of frozen/ thawed ovarian tissue. Hum Reprod. 2010;25:1280-1.

15. Kasai M, Ito K, Edashige K. Morphological appearance of the cryopreserved mouse blastocyst as a tool to identify the type of cryoinjury. Hum Reprod. 2002;17(7):1863-74.

16. Wang XQ, Catt S, Pangestu M, Temple-Smith P. Live offspring from vitrified blastocysts derived from fresh and cryopreserved ovarian tissue grafts of adult mice. Reproduction. 2009;138:527-35.

17. Gosden RG, Baird DT, Wade JC, Webb R. Restoration of fertility to oophorectomized sheep by ovarian autografts stored at -196 degrees C. Hum Reprod. 1994;9:597-603.

18. Raafat AM, Hofseth LJ, Li S, Bennett JM,Haslam SZ.A mouse model to study the effects of hormone replacement therapy on normal mammary gland during menopause: enhanced proliferative response to estrogen in late postmenopausal mice. Endocrinology.1999;140(6):2570-80 .
19. Kawamura K, Cheng Y, Suzuki N, Deguchi M, SatoY, Takae S, Ho C, Kawamura N, Tamura M, Hashimoto S, Sugishita Y, Morimoto Y, Hosoi Y, Yoshioka N, Ishizuka B, Hsueh AJ. Hippo signaling disruption and Akt stimulation of ovarian follicles for infertility treatment. Proc Natl Acad Sci USA. 2013;110 (43):17474-9

20. López-Grueso R, Gambini J, Mohamed K, Monleón D, DíazA, Alami M, Bonet CB, Viña J. Early, butnot late-onset estrogen replacement therapy prevents oxidative stress and metabolic alterations caused by ovariectomy. Antioxid Redox Signal. 2014;20(2):236-46.

\section{Correspondence:}

Luiz Gonzaga Porto Pinheiro

Faculdade de Medicina-UFC

Departamento de Cirurgia

Rua Professor Costa Mendes 1608, $3^{\circ}$ andar, Bloco Didático

60.430-140 Fortaleza - CE Brasil

Tel.: (55 85)3366-8062

Fax: (55 85)3366-8065

cirurgia@ufc.br

Received: Dec 17, 2013

Review: Feb 21, 2014

Accepted: March 18, 2014

Conflict of interest: none

Financial source: none

${ }^{1}$ Research performed at Experimental Animal Laboratory, Department of Surgery, School of Medicine, Federal University of Ceara (UFC), Fortaleza-CE, Brazil. Part of PhD degree thesis, Postgraduate Program in Medical and Surgical Sciences, UFC. Tutor: Luiz Gonzaga Porto Pinheiro. 